\title{
Aquellos barros franceses trajeron estos lodos argelinos
}

\author{
M. ${ }^{a}$ Concepción Ybarra Enríduez de la Orden
}

\section{RESUMEN ABSTRACT}

La guerra de la independencia de Argelia produjo una espiral de violencia indiscriminada que fue la raíz del odio xenofóbico y de la utilización de la fuerza terrorista que hoy dia se está empleando en aquel pais magrebi por diversos grupos enfrentados para conseguir los objetivos propuestos. En este artículo se analizan las causas y consecuencias de los sucesos que ocurrieron durante el conflicto francoargelino en los años cincuenta del siglo $\times x$.

\section{PALABRAS CLAVE} Argelia. Francia. Magreb. África. Independencia. Descolonización.

Terrorismo. Relaciones Internacionales.
Algeria's independence war caused such spiral of violence that was both the source of the foreigner hate and of the use of the terrorist force that nowadays is being applied in that magrebi country by diferent groups to obtain their objetives. The present article, analizes the causes and consecuencies of the events that happened during the franco-algerian conflit in the fifties of the twentieth century.

\section{KEY WORDS}

Algeria. France. Magreb. Africa. Independence. Discolonization. Terrorism. Foreign relations.

Es difícil entender lo que ocurre en Argelia. Raro es el dia en que no aparece alguna referencia en los medios de comunicación sobre asesinatos de civiles o masacres de pueblos enteros en dicho país magrebí. La mayoria de la gente los atribuye al integrismo islámico, pero, ¿conoce acaso la opresión y la humillación a las que estuvo sometida la población 
argelina, durante más de ciento treinta años, por una potencia colonial que dispuso la conquista y la enajenación del antiguo beylato otomano?

Mucho se ha escrito sobre la guerra por la independencia que Argelia sostuvo contra su metrópoli, Francia, desde 1954 hasta 1962, aunque nadie se atrevió a predecir que tres décadas después aún no se habría alcanzado ni un remedo de la democracia occidental ni un régimen islámico puro. El país magrebí más afrancesado y más adelantado en la década de 1960 está labrándose su ruina desde los años noventa a base de crueles enfrentamientos entre el Frente Islámico de Salvación (FIS) y el Gobierno y el Ejército de la nación, que impiden el progreso de una población que sólo desea convivir en paz y prosperidad. Únicamente existe una coincidencia entre los hechos que ocurrieron hace cuarenta años y los que están sucediendo ahora: ni entonces ni en el presente el mundo occidental se ha tomado la molestia de intervenir para mediar en una paz que reconcilie todas las tendencias políticas y las diferencias étnicas de los argelinos. Anteriormente fue Francia la que impidió cualquier intromisión; ahora es el miedo que todas las naciones occidentales, incluso Marruecos, sienten hacia el avance del integrismo islámico, que puede impedir que el poderoso bien económico que Argelia posee, el petróleo y el gas natural, continúe nutriendo a los países mediterráneos vecinos.

Como la información sobre la violencia desatada en Argelia durante los últimos años la obtenemos continuamente a través de los periodistas y analistas políticos, para comprender mejor el problema que vive el país magrebí en estos momentos es preciso conocer sus raíces desde una perspectiva histórica alejada tanto de las razones francesas como de las argelinas.

Argelia, región del mediterráneo norteafricano entre Marruecos y Túnez, ha sufrido numerosas invasiones desde la antigüedad. Bereberes, cartagineses, romanos, vándalos, bizantinos y árabes la han ocupado sucesivamente. Desde la Edad Media ha pertenecido al dominio turco, constituyendo un beylato del Imperio otomano hasta 1830 en que fue conquistada y colonizada por Francia. Tras duros y largos años de luchas y enfrentamientos contra los árabes y bereberes argelinos que se resistían a dicha invasión, llegó a ser considerada parte integrante del territorio nacional francés. La conquista francesa terminó cuando en 1847 se rindió el líder de la resistencia indígena, el emir Abd-el-Kader, el «Defensor de la nacionalidad árabe", el "Comandante de los creyentes de Argelia". También la zona con mayoría bereber, la Kabylia, presentó gran oposición a la invasión francesa. Por fin, las tribus bereberes se rindieron en 1857. En adelante, sólo se produjeron algunas insurrecciones en nombre del Islam, 
confirmando así que los musulmanes argelinos no terminaban de resignarse al colonialismo francés. Sin embargo, Francia consiguió la sumisión del pueblo argelino, la confiscación de sus tierras que fueron ocupadas por colonos franceses y europeos y el despojo del bien más precioso de los índigenas: la libertad de disponer por sí mismos de su país. La colonización francesa se fue produciendo mientras se terminaba la conquista del país.

En 1847 ya se habían instalado en la nueva colonia francesa 110.000 europeos, la mayor parte franceses y el resto españoles e italianos. Otro importante grupo, algo menos numeroso, lo constituían los judíos, antiguos pobladores de la región que nunca se habían integrado completamente en la población musulmana. Se consideraban un núcleo aparte que rápidamente se puso al lado de Francia. En 1870 los judíos consiguieron el derecho a la ciudadanía francesa y a pesar de que siempre se sintieron marginados y despreciados por los colonos y funcionarios franceses, al menos lograron que se respetaran sus propiedades. En 1954 la población argelina constituía más de diez millones de habitantes de la que un millón era de origen europeo. La legislación francesa protegió esta colonización oficial o libre, conseguida por la expoliación de la propiedad indígena. La excusa de este dominio colonial era que Argelia nunca habia existido como nación y que sólo bajo el Estado francés esa "región" magrebí podría lograr una paz y prosperidad duraderas. Sin embargo, no se logró ni una cosa ni otra en el primer siglo de dominación francesa.

A comienzos del siglo $x x$ los jóvenes argelinos comenzaron a tomar conciencia de la necesidad de obtener los mismos beneficios y derechos que los franceses disfrutaban en Argelia. No sólo deseaban la "asimilación" como proponía el Gobierno de París, sino que reclamaban que les fueran reconocidas sus propias peculiaridades lingüísticas, históricas y religiosas. El significado de la palabra independencia se fue introduciendo poco a poco en las conciencias argelinas, mientras iba creciendo la idea de que el colonialismo había detenido al pueblo argelino en su evolución cultural, religiosa y política.

Ya en 1925, Ben Badis, el más célebre reformista del Islam en Argelia explicaba que era necesario salvaguardar la individualidad nacional de los argelinos y restaurar el espíritu nacional ${ }^{1}$. En 1931 Ben Badis fundó la Asociaciación de los Ulemas Argelinos (AOUMA) con el fin de alcanzar el

Charles-Robert AGERON: "Naissance d'une nation", pp. 195 y ss. En L'Algérie des Français, del mismo autor y de VV.AA. 
progreso y la fraternidad sobre la base del Islam y la individualidad nacional en el marco de la soberanía de las leyes francesas. También reclamaba a Francia la salvaguarda de la dignidad de los argelinos, el respeto al Islam y a la lengua árabe, el reconocimiento de la nacionalidad argelina y la unión del mundo árabe-musulmán. Los Ulemas consiguieron definir una doctrina política nacionalista, una ideología moral y social fundada en el carácter árabe-musulmán de Argelia y librar al Islam ortodoxo de las prácticas supersticiosas. Las mezquitas, en su mayoría, fueron el principal soporte para la difusión del mensaje de Ben Badis, el «lslah", y también algunas medersas donde se enseñaba el árabe moderno. El periódico árabe Ach Chibab publicó en abril de 1936 unas declaraciones del jeque Ben Badis en las que aseguraba que siempre había existido una unidad religiosa y lingüística y unas mismas tradiciones culturales: Nous dison ensuite que cette nation algérien n'est pas la France, ni peut être la France et ne veut être la France. El lema de este nuevo credo impartido por la AOUMA era: El Islam es mi religión. El Árabe mi lengua. Argelia es mi país.

Otra corriente nacionalista y revolucionaria que impulsó el sentimiento de repulsa hacia el colonialismo francés y la idea de independencia en Argelia, tuvo su origen entre los obreros argelinos que trabajaban en la metrópoli. El 20 de junio de 1926 fue fundada "La Estrella Norteafricana» a instancias del ejecutivo de la Internacional Comunista, como sección de la "Unión Internacional», aunque no tardó en emanciparse de la tutela del Partido Comunista francés y de su rama argelina liderada por Ferhat Abbas, ya que éstos eran partidarios de la "asimilación" y no de la independencia de Argelia. Desde 1928 «La Estrella» multiplicó sus referencias al arabismo cultural, afirmando la prioridad de la lengua árabe, con un discurso más nacionalista que comunista. El líder de este movimiento, Messali Hadj, afirmaba que "los argelinos deseaban la independencia y no la tutela comunista". En 1933 este movimiento se definia ya como «islamista-nacionalista» siendo sus objetivos combatir el imperialismo francés, la emancipación del Magreb y su independencia total. Tras unos años de persecución por parte del Gobierno francés, Messali constituyó el «Partido del Pueblo Argelino" (PPA) que desde entonces se empeñaría en la creación de un Parlamento argelino, el respeto al Islam y la fundación de escuelas árabes. EI PPA se fue nutriendo con jóvenes nacionalistas argelinos pertenecientes incluso al Partido Comunista de Ferhat Abbas y al de los Ulemas de Ben Badis. Pero Francia prohibió todos sus mítines y actividades proselitistas y Messali fue detenido en 1938 y en 1939, lo que le convirtió en un mártir de la causa. Aunque el PPA llegó a ser disuelto oficialmente por orden del Gobierno francés, se convirtió en un partido clan- 
destino. Durante la Segunda Guerra Mundial muchos de sus militantes estuvieron a favor de Alemania debido a su rencor hacia la metrópoli que tan mal les había tratado.

Así, la ideología nacionalista se fue extendiendo durante los primeros años cuarenta del siglo $x x$ y tras el desembarco aliado en las costas de Marruecos y Argelia a finales de 1942, las esperanzas nacionalistas de emancipación se acrecentaron. Argel se convirtió en la base de la resistencia francesa contra el Eje. El 12 de febrero de 1943 Ferhat Abbas publicó el "Manifiesto del pueblo argelino" donde indicaba que el momento de la "asimilación" ya había pasado y que había llegado la hora de que Argelia reclamara, "en nombre del derecho de los pueblos a disponer de ellos mismos", el fin del régimen colonial. El 26 de mayo de ese mismo año se añadió una cláusula a dicho Manifiesto por la que se exigía la formación de un Estado argelino democrático y liberal y la autonomía de Argelia como nación soberana, aunque con el derecho de fiscalización por parte de Francia. El General De Gaulle, héroe de la Resistencia francesa contra el Eje, sólo prometió a los nacionalistas argelinos que tanto habian cooperado para el triunfo de los aliados en el segundo conflicto mundial, el nombramiento de sesenta y cinco mil electores argelinos junto con los franceses de Argelia y la concesión de la ciudadanía francesa para todos los argelinos que la quisieran. Esta Ordenanza del 7 de mayo de 1944 fue rechazada por todos los nacionalistas; no deseaban ser ciudadanos franceses sino argelinos.

En 1945 cuando fue creada la Liga de las Naciones árabes, la población musulmana de Argelia creyó llegado el momento de declararla nación libre y federada a la Gran Nación árabe. Todos los movimientos nacionalistas argelinos lo reconocieron así y se aunaron cuando el 29 de mayo de 1945 ocurrió la «insurrección de Constantina», tercera ciudad de Argelia tras Argel y Orán, situada al nordeste del país y capital del tercer Departamento francés del mismo nombre. La rebelión del pueblo argelino estalló tras ser asesinado a tiros en Argel un joven árabe por un policía francés. La tensión entre la población argelina y los colonos franceses se desató súbitamente y en Constantina 102 colonos fueron asesinados por rebeldes nacionalistas, éstos fueron reprimidos tan duramente por parte de la policía y el ejército franceses que un balance provisional dio como resultado la muerte o desaparición de cerca de 45.000 argelinos. Este conflicto quedó marcado para siempre en la conciencia de Argelia siendo considerado desde entonces como un "genocidio" que reclamaba la inmediata "Jihad" o Guerra Santa contra el invasor infiel. La "insurrección de Constantina" es la primera etapa más sangrienta de la historia del movimiento nacional argelino antifrancés. 
El PPA, desde ese momento, se convirtió en un partido clandestino con una organización militar secreta, la OS. También fue creado un nuevo partido, el «Movimiento para el Triunfo de las Libertades Democráticas» (MTLD), más respetuoso con la legalidad. En las elecciones legislativas de 1946 fue el partido argelino más votado. Aún en ese año, los nacionalistas que rechazaban el uso de la violencia para conseguir resolver el problema de Argelia crearon otro partido, la «Unión Democrática del Manifiesto Argelino" (UDMA) que reivindicaba la formación de una República argelina asociada a Francia. Bajo la dirección de Ferhat Abbas, este partido de «notables» argelinos, discretamente apoyado por los Ulemas, intentó en vano convencer a los gobernantes franceses de sus legítimas reclamaciones. Los patriotas argelinos, ante la obcecación francesa, comenzaron a dividirse y a acrecentar las filas de los que exigían el uso de la violencia como único medio de conseguir la autodeterminación. Francia, con su intransigencia y su empeño en desarticular la personalidad cultural, económica y religiosa de la población argelina, sin intentar integrarla en un Estado unitario de ciudadanos libres e iguales en derechos y deberes, iba a provocar una rebelión y un odio étnico, religioso y social de imprevisibles consecuencias que durarían hasta la fecha actual.

\section{LA GUERRA DE LA INDEPENDENCIA DE ARGELIA}

En 1954 aún no se había logrado un consenso nacional, sin embargo, el espíritu árabe-argelino ya había adquirido el sentimiento de los valores islámicos más auténticos. Fue entonces cuando algunos militantes de esos partidos nacionalistas, a favor de la acción directa, decidieron la formación de un "Frente de Liberación Nacional» (FLN) con el objetivo de crear un Estado argelino democrático y social en el marco de los principios islámicos. Pronto, este partido se constituyó en el principal partido nacionalista de Argelia y el 1 de noviembre de 1954 su líder, Ben Bella, daría la consigna revolucionaria: Argelia para los argelinos. Los nacionalistas potenciaron un Ejército de Liberación Argelina (ELA) que durante ocho años mantendría a las Fuerzas Armadas francesas en estado de guerra. La revolución argelina se había convertido en la "Guerra de Argelia".

Por entonces, los franceses y sobre todo los de la metrópoli todavía no habian entendido las razones de ese levantamiento armado de la población árabe. Consideraban que Argelia era un conjunto de varios Departamentos franceses e ignoraban que el pais magrebi se había ido transformando, por la explosión demográfica propia del siglo xx y por la destructuración social, en una nación en potencia que no se conformaba 
con las "migajas" de la "asimilación» propugnada por Francia y con las promesas de igualdad política y social que nunca llegaban. Después de tantos años de gastos y conflictos en esa región francesa del norte de África, que no había nunca llegado a ser rentable ni política ni económicamente, las nuevas prospecciones vislumbraban un futuro esperanzador gracias a los hallazgos petrolíferos en el desierto argelino. En estos años cincuenta del siglo xx, Francia se empeñaba en retener su colonia, ahora, sobre todo, por razones económicas. Sin embargo, la población musulmana estaba dispuesta y preparada para luchar por su independencia. Ya se había demostrado la imposibilidad de una coexistencia igualitaria y fraternal. La represión de los motines de Constantina en 1945 y las represalias contra el FLN a comienzos de 1955 así lo atestiguaban. El progreso económico que Argelia denotaba en aquellos momentos, conseguido gracias a las inversiones francesas y a las transformaciones agrícolas e industriales, escondia una realidad más cruda. Los beneficios económicos logrados en ese país revertían sólo en Francia y en los franceses y no en la humilde población campesina o urbana oriunda de esa región. Argelia en estos momentos era un gran exportador de productos agroalimentarios, la Mitidja, planicie situada al sur de Argel, se había convertido por obra de los colonos franceses en una modélica región agrícola, sus viñedos constituían la mayor riqueza de la comarca. Argelia disponía, asimismo, de la mejor infraestructura del continente africano después de Suráfrica y la venta de hidrocarburos componía el $12 \%$ de sus exportaciones ${ }^{2}$. Estas mejoras económicas no se correspondian con las sociales; se negaba a la población la enseñanza árabe y la explotación humana se centraba en los argelinos musulmanes que no conseguian la misma calidad de vida que sus convecinos franceses, los «pieds-noirs" ${ }^{3}$, por lo que el deseo de emancipación comenzaba a arraigar profundamente en todos los corazones árabes.

La Guerra de Argelia fue uno de los acontecimientos que más repercusiones han tenido en los movimientos de liberación de los pueblos oprimidos. El método más utilizado para conseguir la independencia en Argelia fue la aplicación de la violencia indiscriminada, vulgarmente llamada "terrorista" ${ }^{4}$. Sin embargo, no fueron los argelinos quienes inventaron esta

Juan Govtisolo: Argelia en el vendaval, p. 13

El apelativo "pieds-noirs" fue utilizado para denominar a la población francesa que colonizó Argelia a finales del siglo xix, dedicándose en su mayoría a plantar viñedos con cepas americanas del tipo "pied-noir" er. los momentos en que la filoxera arruinaba los viñedos europeos.

4 Guy PERVILLE: "Le terrorisme dans la guerre d'Algérie (1954-1962)", pp. 207-223, en L'Algérie des Français de Charles-Robert Ageron, (ob. cit.). 
práctica de presión, que ya desde el albor de los tiempos todas las sociedades la han utilizado en mayor o menor grado. Un ejemplo bien cercano lo constituyó la Segunda Guerra Mundial. En ella ambos bloques contrincantes aplicaron varias especies de "terrorismo": bombardeo masivo de ciudades habitadas por gente inocente; campos de concentración de diversos grupos de personas, judíos, católicos, gitanos, comunistas, etc., siendo su única culpa ser "diferente» o pertenecer a un grupo distinto del de su agente dominador; el fusilamiento indiscriminado, sin distinguir sexo - edad; la tortura psicológica a diversas poblaciones; la imposición del «terror"... En fin, parecía que esta guerra universal había disculpado estas suertes de «terrorismos" de Estado. Del mismo modo, los rebeldes argelinos consideraron legítimo y eficaz utilizar todos los medios a su alcance para conseguir la liberación de su país. Aunque no sólo utilizaron la violencia, también consideraron que se debia realizar todos los esfuerzos propagandísticos y diplomáticos posibles, tanto en el interior como en el exterior de Argelia. En el Cairo se había formado ya el Comité de Liberación del Magreb del que formaban parte los principales líderes argelinos del FLN, Ben Bella y Budiaf, junto con Abdelkrim y Allal el Fassi, líderes del nacionalismo marroquí y Burguiba, presidente del partido Neo-Destour tunecino. Desde Egipto se trabajaba para convencer a las potencias occidentales de la necesidad de lograr la emancipación total del Norte de Árrica; se enviaban representantes a la Liga Árabe para que ésta defendiera la justa causa del Magreb, se emitian programas de radio, artículos en la mayoría de los periódicos árabes y se influía en la sede de la ONU para lograr la independencia de los paises árabes sometidos a Francia. No obstante, todos estos esfuerzos no servían de nada ante la obcecación del Estado francés en mantener su dominio en todo el Magreb.

Cansado de la impasibilidad francesa, el FLN decidió aplicar el método más duro para conseguir la liberación de Argelia. Así, «en la noche del 31 de octubre al $1^{\circ}$ de noviembre de 1954 , grupos rebeldes argelinos cometieron una treintena de atentados, especialmente al este del Departamento de Constantina y en el Aurés. Varios puestos de policía fueron atacados, se lanzaron gran número de bombas y los incendios provocados se propagaron por doquier' ${ }^{5}$. Esta serie de atentados, que causaron 8 muertos, de ellos 4 militares, 2 civiles europeos y 2 musulmanes, fueron reivindicados por el FLN y su rama militar el ALN en una serie de folletos propagandísticos firmados por esas organizaciones nacionalistas. Los

Documentos Dipiomáticos Franceses (DDF), 1954. Vol. I, n²313, pag. 648: Informe del Ministro Fouchet. 4/11/54. 
franceses fueron lo primeros que aplicaron el término "terrorista" para designar la actuación del FLN contra Francia. Los dirigentes argelinos no lo consideraron así, ellos anunciaban "la continuación de la lucha por todos los medios hasta la realización de nuestro objetivo, conforme a los principios revolucionarios" ${ }^{6}$. El 31 de octubre, el ALN habia efectuado una llamada a los argelinos en la que les exhortaba a sostener por todos los medios a su alcance a sus hermanos combatientes como deber islámico y patriótico inexcusable, de esa manera se estaría sirviendo a la causa, porque desinteresarse de la lucha sería un crimen y una traición. Los «mud. jahidine", soldados de la guerra santa, estaban convencidos de que Dios está con los que luchan por las causas justas y de que por el ejemplo de Mahoma, quien castigaba a los apóstatas y traidores, ellos deberían hacer lo mismo con quienes no les ayudaban. El movimiento clandestino del nacionalismo argelino necesitaba contar con el apoyo de su pueblo para afirmar ante el mundo su legitimidad. A partir del instante de la insurrección, el terrorismo aplicado contra los franceses en Argelia fue seguido por la ejecución de los «traidores" musulmanes que defendian la permanencia de Francia en Argelia.

La eficacia de ese método de presión pronto fue demostrada como se comprueba por el contagio que experimentaron otros grupos paramilitares. Así ha sucedido en la misma Argelia con la Organización de la Armada Secreta (OAS), compuesta por varios militares y civiles franceses, pieds-noirs, que no estaban dispuestos a que esa "provincia" francesa se convirtiera en una nación árabe. En marzo de 1961 se dio a conocer por esas siglas la red de activistas opositores a la política de abandono que estaba llevando a cabo el Gobierno galo. Estos pieds-noirs agrupaban cerca de un millón de personas; 400.000 de origen francés, 400.000 europeos, en su mayoría españoles, 50.000 judíos de origen indígena, quienes desde 1871 se habían convertido en ciudadanos franceses, y algunos feudales y funcionarios argelinos a los que no interesaba la independencia de su país porque corrían el peligro de perder sus privilegios. La mayoría de los franceses-argelinos estaba de acuerdo en practicar el "contra-terrorismo" frente a los nacionalistas y separatistas, era la última carta que les quedaba por jugar. En mayo de 1958, cuatro años después de comenzar la guerra de liberación, los europeos de Argelia solicitaron a De Gaulle, como nuevo Jefe del Gobierno de la República francesa, que practicara la integración en esa región magrebí. En aquel momento, el Gobierno de París estaba dispuesto a que Argelia continuara siendo francesa y el

\footnotetext{
6 Guy Pervillé: "Le terrorisme dans la guerre d'Algérie (1954-1962" p. 208. (Ob. Cit.).
} 
mismo De Gaulle, en un discurso esperanzador, utilizó la famosa frase "Yo os he comprendido", lo que provocó un gran entusiasmo en la población francesa de Argelia que creyó que ya había ganado la guerra. Pero cual fue su desilusión cuando en septiembre de 1959, el ya Presidente de la V República, General De Gaulle, habló de "autodeterminación" para esa región norteafricana. Desde entonces los pieds-noirs se decidieron a practicar el terrorismo indiscriminado, aunque ya no sería sólo la población musulmana quien lo sufriera, sino también los mismos franceses adictos al Gobierno de De Gaulle.

Durante los siete años y medio que duró la Guerra de Argelia, se practicó todo tipo de «terrorismo». Incluso el Gobierno francés permitió la utilización de todos los medios a su alcance para reprimir la insurrección argelina. Fueron masacrados pueblos enteros con la sola sospecha de su connivencia con los rebeldes. El Gobernador General, Jacques Soustelle, permitió a las fuerzas del orden practicar crueles represalias y fechorías sin nombre, como la ejecución inmediata de argelinos sorprendidos con cualquier tipo de arma, violaciones de musulmanas, vejaciones a los cadáveres y un sin número de indignidades, de la misma manera que los rebeldes cometían sus propias iniquidades. Tanto para las autoridades francesas como para el FLN y la OAS, la violencia indiscriminada y la represión más crudamente practicada se convirtió en el arma esencial del combate. Asi, el terrorismo practicado en Argelia por ambas partes enfrentadas, provocó de un lado la creación de un odio profundo entre franceses y argelinos, xenofobia que dura hasta la fecha y de otro, la unidad de todos los musulmanes magrebies.

¿Por qué ante tanta barbarie los Gobiernos internacionales no actuaron para solucionar este conflicto?. En 1954 los países árabes del Magreb bajo el dominio francés, como Túnez y Marruecos, ya estaban luchando para conseguir su liberación. La Liga Árabe les daba su apoyo y los Estados Unidos aconsejaban a Francia que llegara pronto a una solución. Sin embargo, fue España la única nación occidental que parecía apoyar las reivindicaciones nacionalistas del Magreb. Sus motivos no eran altruistas o humanitarios, ni siquiera descolonizadores, ya que todavía estaba dispuesta a continuar ejerciendo su dominio en el Protectorado español de Marruecos y en el Sáhara occidental y Guinea. La ayuda que, durante los primeros años de la guerra, el Gobierno español concedió al FLN y a sus líderes estuvo motivada por la necesidad de seguir contando con la amistad del mundo árabe y también como medio de presión contra Francia, su rival tradicional en Marruecos. Cuando aún estaba siendo negociada la independencia del Protectorado de Marruecos y Francia seguía imponiendo su criterio tanto a España como al país alauíta, los rebeldes argelinos li- 
derados por Ben Bella y Budiaf entraban y salían de España sin impedimento alguno. En Madrid se reunían con sus adeptos norteafricanos bajo la mirada atenta de las autoridades españolas. En esos momentos el Gobierno español y sobre todo el Alto Comisario en Marruecos, General García Valiño, estaban propiciando el nacionalismo rifeño. Por la frontera marroco-argelina, vigilada por las fuerzas francesas y españolas, se pasaba armamento destinado a la guerrilla argelina ? Francia acusaba a España de connivencia con los rebeldes y aunque ésta lo negaba, existen indudables pruebas del apoyo español a la revolución argelina hasta $1958^{8}$.

El 22 de octubre de 1956, seis meses después de haber conseguido los Protectorados de Marruecos y Túnez su independencia, ocurrió un suceso por el que España estuvo, sin querer, involucrada en la "cuestión de Argelia". Los dirigentes árabes de estos dos paises, el rey Mohamed $V$ y el Presidente del Gobierno tunecino Habib Burguiba, habían convocado en Túnez una cumbre magrebí con el fin de sellar el "Pacto de amistad marroco-tunecino" y participar en el proyecto de pacificación de Argelia, al que estaban invitados también los líderes argelinos más representativos. Mientras el sultán de Marruecos abandonaba Rabat, por avión, a las 11 de la mañana y aterrizaba en Túnez a las 5 de la tarde, acompañado por el príncipe Hassan, el Presidente de Gobierno marroquí, Si Bekkai y por cinco ministros más, otro aparato con tripulación y matricula francesas, aunque perteneciente a la Compañía Jerifiana de transportes aéreos (sociedad marroquí con mayoría de capital trancés), despegaba de Rabat con dirección a Túnez, llevando a bordo a los cinco jefes de la rebelión argelina, Ahmed ben Bella, Mohamed Khider, Mohamed Boudiaf, Hocein Aït Ahmed y Mustafá Machraf, quienes habían sido en los últimos días huéspedes del Rey Mohamed V. Este avión, después de haber hecho escala en Palma de Mallorca, al despegar rumbo a Túnez, fue rápidamente obligado a dirigirse hacia Argelia, por orden de las autoridades militares de la $X^{a}$ Región francesa comandadas por el Ministro de Defensa. Nada más aterrizar en el aereopuerto de Argel, los líderes argelinos fueron arrestados por las fuerzas francesas. Esta afrenta cometida por Francia contra unos invitados de los Gobiernos de Túnez y Marruecos no sólo colocaba a Mohamed $V$ y a Burguiba en una mala situación ante sus hermanos árabes, sino que también España se podía encontrar involucrada ya que sobre su

Archivo del Ministerio de Asuntos Exteriores (AMAE), legajo R-4.293 exp. 1 y R-5.004 exp. 6: Contrabando de armas en la frontera marroco-argelina. Actividades de los rebeldes argelinos. $15 / \mathrm{X} / 1955$.

8 DDF Vol. I $n^{\circ}$ 328: El embajador francés en España, La Tournelle, expresa sus protestas al Ministro español de Exteriores, Martín Artajo, sobre "la cuestión de Argelia". 19/V/1956. 
espacio aéreo se había cursado la orden del secuestro. La ayuda constante que el Gobierno español había prestado a los líderes argelinos, cuestionaba la posible decisión de una intervención española en dicho asunto ${ }^{9}$. Pero Madrid sólo se limitó a protestar al Ministro francés de Exteriores por la vulneración de su espacio aéreo, sin tomar medidas más contundentes para defender a los jefes del Gobierno Revolucionario argelino.

Tampoco los demás países occidentales quisieron intervenir en la arbitraria decisión francesa, aunque tanto el FLN como la Liga Árabe recurrieron a los Estados Unidos y a la ONU denunciando «el atentado flagrante contra las libertades fundamentales previstas por la Carta de las Naciones Unidas y contra los principios proclamados por la Declaración de los Derechos del Hombre, y que además constituye una derogación de las reglas del Derecho de Gentes y de las disposiciones de los Tratados y Acuerdos Internacionales". El Consejo de la Liga, reunido en el Cairo en sesión urgente el 23 de octubre, solicitaba del Secretario de la ONU que informara a todos los Estados miembros sobre las violaciones cometidas por Francia que agravaban la paz y la seguridad mundiales y rogaba que hiciera todo lo que estuviera en su mano para salvar la vida de los líderes argelinos, garantizar su seguridad y conseguir su libertad. Se reafirmaba también el total apoyo de la Liga Árabe a la causa argelina ${ }^{10}$.

Sin embargo, ni la ONU ni los Estados Unidos emprendieron ninguna acción punitiva contra Francia. El Gobierno británico consideró «increíblemente estúpida" esa acción francesa que estaba causando peligrosas posibilidades de enfrentamiento. Opinaba que la actuación francesa iba a precipitar la unión entre Egipto y Marruecos que arrastraría a sus vecinos magrebíes y entonces todo el norte de África quedaría en la órbita egipciorusa, con el peligro que eso traería a Occidente ${ }^{11}$. Pero Inglaterra no podía presionar a Francia porque en esos mismos momentos era su aliada más ferviente en la "Crisis del Canal de Suez". Mientras se producía el secuestro del avión marroquí con los líderes argelinos, el ministro francés de Asuntos Exteriores se reunía en París con el ministro de Exteriores británico y con el Jefe del Estado israelí Ben Gourion para acordar el ataque conjunto de la zona del Canal de Suez y lanzar un «ultimatum» a Egipto.

\footnotetext{
9 M.a Concepción YBaRRA: La descolonización del Magreb. Rivalidad hispano-francesa en Marruecos . 1998. Cap. XV.

10 AMAE. Leg. R-4.539. Exp. 23: Reacción de los países árabes ante la politica francesa en Argelia. 25/X/1956.

11 Foreign Office. Public Record Office (F.O./PRO). 371/119: Relaciones politicas entre Marruecos y Francia. 23/X/1956.
} 
Francia tenía en esos momentos demasiados problemas coloniales. Este conflicto fue llevado con urgencia al Consejo de Seguridad de la ONU y se acordó impedir el enfrentamiento armado obligando a Inglaterra y a Francia a cesar en sus ataques invasores en la zona del Canal. La URSS se aprestó a ayudar a Egipto y también los Estados Unidos tuvieron que amenazar con su intervención en "contra" de sus "aliados" Francia, Inglaterra e Israel, rompiendo así la armonía del bloque occidental. Sin embargo, la "cuestión argelina» no fue debatida ni por la ONU ni por los Estados Unidos, el anticolonialismo propugnado por los norteamericanos y que tanto habia impulsado a los nacionalistas árabes en su afán liberador, no se demostró en este conflicto franco-argelino. Incluso se permitió a Francia que fuera aumentando las tropas que desde la metrópoli enviaba hacia Argelia bajo el mando de la OTAN, empleando armas proporcionadas por la ayuda militar americana.

El descabezamiento de la cúpula del FLN, iba a proporcionar a Francia muy pocos beneficios ya que a los nacionalistas argelinos les costó poco tiempo reponer sus mandos. Los secuestrados permanecieron presos en Francia hasta poco antes del armisticio en 1962, no obstante, a finales de 1956 el FLN y su rama armada el ALN habían conseguido reforzar sus efectivos y su organización. Querían que su «Movimiento Nacional» estuviera estructurado conforme al derecho internacional (personalización del ejército, poder político reconocible, respeto a las leyes de la guerra, administración normalizada en las zonas liberadas). Se crearon una jerarquía militar y una Organización político-administrativa (OPA), reunidas bajo el mando de jefes político-militares en el marco de seis "Wilayas" (provincias), y a escala nacional dos órganos dirigentes, el Consejo nacional de la revolución argelina (CNRA) y el Comité de coordinación y de ejecución $(\mathrm{CCE})^{12}$. Los líderes secuestrados se convirtieron en mártires de la causa ante los ojos del mundo y el odio antifrancés se acrecentó en todos los paises musulmanes, donde se produjeron numerosas manifestaciones de repulsa contra Francia. Durante 1957 la directiva del FLN, asilada en Túnez, consiguió de este país numerosas partidas de armas con el consiguiente disgusto del Gobierno francés ${ }^{13}$ que veía asi incrementarse los atentados terroristas perpetrados por los rebeldes argelinos. Las relaciones franco-tunecinas se iban deteriorando a causa del apoyo ofrecido por el anti-

\footnotetext{
12 Guy PeRVILLĖ: La France n'avait pas perdu la guerre... Pp. 249-250, en L'Algerie des Français. (Ob. cit.).

13 DDF, 1957. Vol. I, $\mathrm{n}^{\varepsilon}$ 434: El Ministro francés de Asuntos Exteriores informa a los representantes diplomáticos de varios países occidentales del tráfico de armas efectuado por Túnez en beneficio del FLN. 30/V/1957.
} 
guo Protectorado francés a la guerrilla argelina. Asimismo, el FLN denunciaba al Consejo de Seguridad de la ONU la responsabilidad de Francia en la masacre de la localidad argelina de Melouza, llevada a cabo por fuerzas del ejército francés el 28 y 29 de mayo de ese mismo año. Sin embargo, era tanta la presión de Francia para que no se discutiera la «cuestión argelina" en los foros internacionales, que los países aliados procuraron mantenerse al margen del conflicto.

Hasta 1958 los enfrentamientos continuaron sin cesar, el terror invadía las calles de las ciudades argelinas. Por doquier estallaban bombas que fulminaban a la población civil y las represalias francesas se hacían más y más frecuentes. La venganza se generalizaba en todas partes, los musulmanes mataban a los europeos y éstos hacían lo mismo con aquéllos. Francia vivía una crisis externa e interna motivada por la "guerra de Argelia», hasta que el 13 de mayo de 1958 se produjo un golpe militar en Argel, a consecuencia del cual volvió al primer plano de la política francesa el general Charles De Gaulle. El Gobierno de Francia presidido por Pierre Pflimlin, que contaba con el apoyo de los parlamentarios comunistas, habia anunciado que concedería elecciones libres en Argelia: este fue el detonante del levantamiento contra París de la cúpula militar de la colonia francesa. Bajo la dirección del general Jacques Massu, fue creado ese mismo día en Argel un "Comité de Salvación Pública", compuesto por los generales Sid Cara, Jacques Soustelle, Raoul Salan y León Delbecque. Los golpistas pidieron al general De Gaulle, que se hallaba retirado en Colombeyles-Deux-Églises, que salvara a Argelia del abandono. El Gobierno de París cayó y no le quedó otro remedio al Presidente de la IV República René Coty que pedir a De Gaulle que se hiciera cargo de la dirección de Francia. El General anunció que iba a elaborar una nueva Constitución y que resolvería el conflicto argelino. Esto causó un gran júbilo entre los pieds-noirs argelinos, que veían con esperanza el final de la guerra y la continuación de una "Argelia francesa". El 28 de septiembre de 1958 fue aprobada la nueva Constitución francesa por referendum nacional y el 21 de diciembre De Gaulle fue elegido Presidente de la V República francesa.

A pesar del cambio político efectuado en Francia, los combates en Argelia no cesaron, incluso el FLN llevó la guerra a la metrópoli cometiendo numerosos atentados en París, aprovechando la crisis interna que estaba viviendo el país galo. Al Presidente francés no le quedó otro remedio que llegar a la negociación con el clandestino Gobierno Provisional de la República Argelina (GPRA) que había sido proclamado por el FLN el 19 de septiembre de 1958 en el Cairo. El Presidente francés comenzó por retirar los poderes militares y civiles a la cúpula golpista de Argelia. Sustituyó al general Salan por un delegado general, Paul Delouvrier y por un coman- 
dante en jefe del ejército, Maurice Challe. El primero fue encargado de aplicar reformas administrativas, económicas y sociales con la intención de elevar el nivel de vida de los argelinos, el segundo tuvo por misión vencer rápidamente al sector rebelde que había rehusado aceptar las ofertas de paz que el Presidente les había hecho el 4 de junio de 1959. El 3 de octubre de 1958 De Gaulle propuso una solución para terminar con el «terror", tanto en la metrópoli como en su colonia magrebí. Este plan de reformas, conocido como el «Plan de Constantina» consistía en celebrar un referendum por el que los franceses deberían decidir si aceptaban negociar con el FLN y llegar así a la pacificación de Argelia. Cada vez eran más numerosos los países que habian reconocido al Gobierno Provisional de la República Argelina, liderado por Ferhat Abbas, quien había enviado un texto al grupo de países africanos de la ONU explicando que la posición de su Gobierno estaba muy clara: "deseamos establecer la paz en África del Norte y un arreglo negociado del problema argelino, no rechazamos la propuesta de negociación del Gobierno francés pero no se nos puede exigir que cesemos el fuego hasta que la situación de Argelia no se haya arreglado y el pueblo argelino haya conseguido su independencia" ${ }^{14}$. Estas declaraciones fueron muy mal acogidas por el Gobierno francés y por los militares y población francesa de Argelia quienes decidieron acabar con el problema continuando con la dura represión. En 1959 los atentados organizados por los comandos de la OAS se volvieron tan brutales como los de los rebeldes argelinos. Los franceses utilizaban cargas de plástico en todos los lugares en donde se concentraba la población musulmana. Los terroristas favorables a la "Argelia francesa" fueron llamados desde entonces "plastiqueurs" por utilizar ese material en sus explosiones mortíferas. Este grupo de presión francés, ante la desesperada situación argelina, fue cobrando cada vez más fuerza por la utilización de la violencia indiscriminada, y su oposición al Gobierno de De Gaulle, al que consideraban un traidor por querer negociar con los rebeldes para solucionar el conflicto argelino, culminó en un golpe militar en 1961.

En cambio, desde 1960 el GPRA se fue haciendo más popular entre la población musulmana que ya veía en él su única salvación. El 10 y el 11 de diciembre de ese año se produjeron manifestaciones en Argel y en otras grandes ciudades, como Orán y Constantina, aclamando al Partido argelino, que lograron numerosas repercusiones internacionales de gran alcance a favor de la independencia de Argelia. Fue entonces cuando De

\footnotetext{
14 DDF. 1958. Vol. II, $\mathrm{n}^{\circ}$ 290: El representante francés en las Naciones Unidas informa a su Ministro sobre la declaración del enviado por el FLN a la ONU.
} 
Gaulle llegó al convencimiento de que la única manera de llegar a la paz era negociando un acuerdo con el GPRA. El General renunciaba así a la victoria francesa. Sin embargo, los generales de Argelia no estaban de acuerdo con esa postura y el 22 de abril de 1961 provocaron un levantamiento contra De Gaulle, el llamado «Putsch de los generales», es decir la tentativa realizada por los generales Challe, Zeller, Jouhaud y Salan para volver a tomar el mando del ejército con el fin de ganar la guerra en tres meses. Este golpe militar falló estrepitosamente y el Presidente francés actuó de inmediato destituyendo a todos esos militares y retirando de Argelia varias divisiones del ejército. A continuación emprendió negociaciones con el GPRA, decidido ya a llegar a la autodeterminación del país magrebí. Fue entonces cuando los dirigentes de la OAS hicieron proclamar su Organización en los medios públicos y tomaron la dirección del enfrentamiento francés contra los rebeldes argelinos.

No sólo la OAS se oponía a De Gaulle, también el Gobierno español estaba dispuesto a defender ese movimiento, aunque anteriormente hubiera dado su apoyo a los nacionalistas argelinos. En España se había creado una corriente de opinión en contra del Presidente francés desde que comenzaron las dificultades con el nuevo Estado de Marruecos. El resentimiento español se acrecentó al contemplar cómo Francia era otra vez la beneficiada en las relaciones con Marruecos. El apoyo que De Gaulle estaba prestando al príncipe Hassan en la represión de los rebeldes rifeños había provocado la basculación de la actitud española en el conflicto argelino. Franco concedió asilo a los generales y miembros de la OAS que se refugiaban en España tras el juicio celebrado en Paris contra los protagonistas del fallido "putsch de los generales». El Gobierno español prestaba ayuda financiera y seguridad personal a importantes personajes del movimiento de los «ultras» franceses. Tanto el general Raoul Salan como su lugarteniente y miembro de la Asamblea francesa, Pierre Lagaillarde, principales acusados en el proceso contra los miembros de la OAS, se movían por España con toda facilidad. Desde Madrid, incluso, preparaban los futuros atentados que sus comandos provocaban en $\mathrm{Ar}$ gelia. Pese a contar con tanta ayuda, no sólo de España sino también de la misma Francia, la OAS se encontró perdida cuando en marzo de 1962 se firmaron «los Acuerdos de Evian» entre el Gobierno del FLN y el Gobierno francés y se puso en libertad al jefe de los nacionalistas argelinos, Ahmed Ben Bella. Se concertó el "alto el fuego" en Argelia y se preparó un referendum que decidiría la independencia del país. La OAS, en esos últimos meses, desató sus últimas ofensivas causando un gran número de muertos entre la población argelina y practicando su política de «tierra arrasada" para así dejar un país arruinado a los argelinos. 
El 3 de julio de 1962 se consiguió el triunfo de la tesis propugnada por los nacionalistas argelinos: Argelia para los argelinos. El referendum celebrado proclamaba la independencia de Argelia. Los dirigentes de la OAS habían sido detenidos y juzgados y casi todos los colonos habían abandonado ya la antigua colonia francesa.

\section{CONCLUSIONES}

Los colonos franceses o europeos que se instalaron en Argelia desde el siglo XIX y sus descendientes, los verdaderos "pied-noirs", no fueron los culpables del drama que se vivió y aún se vive en ese país magrebí. La emigración hacia Argelia se realizó por motivos políticos o económicos. Se abria una nueva región a Europa, promesa de una mejor vida. Los gobernantes franceses dieron a los franceses y europeos que se instalaron en Argelia grandes facilidades, tanto legales y económicas como protectoras. Éstos creyeron legítimo acceder al derecho de posesión de unas tierras o bienes materiales. Fueron trabajadores esforzados que intentaron transformar la economía de la región, claro que en su propio beneficio y no en el de las poblaciones autóctonas. Nunca comprendieron que el humilde campesino, artesano o comerciante, antiguo habitante del país, pudiera sentirse despojado y humillado por la expropiación de sus tierras y bienes y por el desprecio hacia su raza, religión y costumbres. Los franceses, como ocurre con la mayoría de los colonizadores universales, siempre consideraron que la presencia de su nación en el norte de África, era una buena obra porque aportaba progreso y civilización a un pueblo atrasado y revuelto. Hoy día, el mundo civilizado, o lo que entendemos como tal, ya sabe que toda imposición de una cultura, religión, política o modo de vida es ilegal e inmoral. Que existen otros medios para lograr que los pueblos salgan de su pobreza, atraso o crisis política y social. Que es justo que toda nación se gobierne por sí misma, sin intromisiones interesadas, aunque su situación económica y política sea catastrófica y constituya una tentación de conquista "reparadora».

Tampoco la población argelina ha sido la causante de tanta destrucción y terror. Siempre ha sido sometida por unos o por otros, ya fueran invasores o dirigentes propios. Pero es necesario entender que cuando la libertad está cercenada, cuando la humillación hiere el ánimo, cuando la miseria se introduce profundamente en el pueblo colonizado o sometido, mientras el conquistador o mandatario va mejorando su calidad de vida a costa de la población autóctona o inculta, el caldo de cultivo revolucionario germina fácilmente en todas las gentes sojuzgadas. Sin embargo, ¿por 
qué tras la independencia, Argelia no ha conseguido ni la paz ni el progreso que tanto anhelaba?. Es difícil encontrar la solución de esta cuestión. Durante mucho tiempo el FLN, triunfador de la revolución, ha gobernado el país con mano de hierro. La población musulmana no ha salido de su miseria pese a contar con suficientes recursos naturales, como los hidrocarburos explotados en el desierto argelino. Ha sido preciso que otro movimiento liberador como el Frente Islámico de Salvación (FIS) tome la antorcha de la revolución e incite a las masas a luchar por sus derechos. La violencia se contagia, la sangre enloquece, la crueldad se acrecienta en colectividad, el odio ciega las mentes. Si el Estado invasor o el Gobierno dictador utiliza la fuerza y la represión indiscriminada para someter al pueblo, éste, más tarde o más pronto, también la utilizará para conseguir su libertad. Entonces se produce una cadena destructora interminable que "aterroriza" a unos y a otros contrincantes y que sólo termina cuando existe voluntad pacificadora, cuando se utiliza la negociación que impulsa a uno y otro bando a ceder algunas reivindicaciones para llegar al acuerdo final. De esta manera se podrán olvidar las afrentas, el odio se cambiará por tolerancia y las ciegas venganzas se tornarán en perdón y en esperanza de paz. 